Full length article

\title{
Platelet lysate-based pro-angiogenic nanocoatings
}

\author{
Sara M. Oliveira, Rogério P. Pirraco, Alexandra P. Marques, Vítor E. Santo, Manuela E. Gomes, Rui L. Reis, \\ João F. Mano*
}

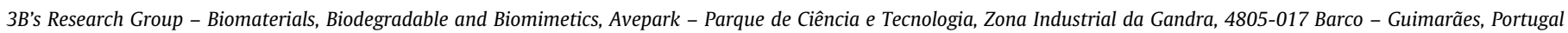
ICVS/3B's - PT Government Associate Laboratory, Braga/Guimarães 4805-017, Portugal

\section{A R T I C L E I N F O}

\section{Article history:}

Received 2 September 2015

Received in revised form 10 December 2015

Accepted 15 December 2015

Available online $\mathrm{xxxx}$

\section{Keywords:}

Layer-by-layer assembling

Instructive surfaces

Platelet lysate

Growth factors

Angiogenesis

Endothelial cells

\begin{abstract}
A B S T R A C T
Human platelet lysate (PL) is a cost-effective and human source of autologous multiple and potent pro-angiogenic factors, such as vascular endothelial growth factor A (VEGF A), fibroblast growth factor b (FGF b) and angiopoietin-1. Nanocoatings previously characterized were prepared by layer-by-layer assembling incorporating PL with marine-origin polysaccharides and were shown to activate human umbilical vein endothelial cells (HUVECs). Within $20 \mathrm{~h}$ of incubation, the more sulfated coatings induced the HUVECS to the form tube-like structures accompanied by an increased expression of angiogenicassociated genes, such as angiopoietin-1 and VEGF A. This may be a cost-effective approach to modify 2D/3D constructs to instruct angiogenic cells towards the formation of neo-vascularization, driven by multiple and synergistic stimulations from the PL combined with sulfated polysaccharides.
\end{abstract}

\begin{abstract}
Statement of Significance
The presence, or fast induction, of a stable and mature vasculature inside 3D constructs is crucial for new tissue formation and its viability. This has been one of the major tissue engineering challenges, limiting the dimensions of efficient tissue constructs. Many approaches based on cells, growth factors, 3D bioprinting and channel incorporation have been proposed. Herein, we explored a versatile technique, layer-by-layer assembling in combination with platelet lysate (PL), that is a cost-effective source of many potent pro-angiogenic proteins and growth factors. Results suggest that the combination of PL with sulfated polyelectrolytes might be used to introduce interfaces onto $2 \mathrm{D} / 3 \mathrm{D}$ constructs with potential to induce the formation of cell-based tubular structures.
\end{abstract}

() 2015 Acta Materialia Inc. Published by Elsevier Ltd. All rights reserved.

\section{Introduction}

The development of tissue engineering constructs containing a functional and mature pre-vasculature is still a major challenge [1-3]. In the absence of such a network, the viability and regeneration potential of thick constructs will be compromised due to the limitation of nutrients and cell debris diffusion. In order to overcome this issue, researchers have been recurring either to material-based and cell-based approaches aiming to create an adequate vasculature inside engineered constructs. Material-based approaches have been focusing on the development of cellular or acellular 3D organized vessel-like structures through microfabrication and customized cell seeding methodologies [4,5]. On the other

\footnotetext{
* Corresponding author at: University of Minho, 3B's Research Group, Avepark - Parque de Ciência e Tecnologia, Zona Industrial da Gandra, 4805-017 Barco - Guimarães, Portugal.

E-mail address: jmano@dep.uminho.pt (J.F. Mano).
}

hand, cell-based approaches have been centered the instruction and activation of the involved angiogenic cells (e.g., endothelial and pericytes) to lead their cellular assembling into stable cellular tubular networks (i.e., tubulogenesis). The specific instruction of endothelial cells (EC) towards the formation of stable tube-like structures (TLS) has been extensively investigated [6,7]. Natural or synthetic extracellular cues such as collagen, fibrin, growth factors (GFs) or similar epitopes, are known to activate specific integrins and tyrosine kinase receptors, efficiently promoting angiogenic cells activation and formation of TLS. However, most of those instructive cues/constructs are frequently obtained from animalorigin and costly sources, or need complicated procedures. The formation of neo-vessels involves a complex crosstalk between several cell types, platelets releasates, extracellular matrix and their secreted pro and anti-angiogenic factors. Vascular endothelial growth factor (VEGF) and fibroblast growth factor $\mathrm{b}$ (FGFb) are considered the most potent angiogenic GFs being frequently used to 
prepare angiogenic biomaterials. The angiogenesis is initiated and regulated by several cells types, GFs and other bioactive proteins and environmental cues such as hypoxia [8]. The ECs are activated, proliferate, migrate and, in the final stage, their tubular structures are stabilized by pericytes, smooth vascular cells and synthetized ECM [8].

Recent works have been highlighting the importance of the provision of multiple GFs in order to achieve better networks regarding size features and stability [1,9-12]. This has been explored by the combination of multiple recombinant GFs or other cell types able to provide such bioactive moieties to the EC. Platelets, natural players in the healing process, are very attractive sources of multiple GFs, metalloproteinases and other potent regulators of angiogenesis [13].

The ability of platelets derivatives to stimulate ECs proliferation, migration and enhance in vitro and in vivo angiogenesis has been recently reported $[9,14-20]$. These features has been mainly attributed to platelet-rich-plasma (PRP). PRP has been mixed with biomaterials [9,18,19], adsorbed onto scaffolds [20], used as PRP-gel [17] or by itself [14-16]. Moreover, reports have shown that PRP, used as extract in GFs-reduced Matrigel, can promote the formation of tube-like structures (TLS) of ECs within less than $24 \mathrm{~h}$, which reinforces its angiogenic potential [14-16]. However, Matrigel or other similar rich basement membranes are from animal sarcoma origin, thus are not considered a suitable option for human application [21].

Herein, we propose the reconstruction of angiogenic nanobasement membranes-like constructs by using platelet lysate (PL) - as a source of multiple angiogenic factors-, marine-origin polysaccharides - as stabilizers -, and layer-by-layer assembling (LbL) - for a controlled assembling - Fig. 1a. PL was obtained by lysing human platelet concentrates by freezing-thawing cycles - Fig. 1b.

LbL is a simple and versatile technique comprising the alternated deposition of polyelectrolytes (PEs) interacting by electrostatic, or other types of interactions, and can be performed under mild conditions [22-24]. In order to achieve an efficient EC activation mediated by GFs, their stability, conformation and density presented to the cells must be adequate. Moreover, the type of binding between the GF and their stabilizer will affect the intracellular signal transduction [25] - Fig. 1c. Under this context, several PEs were assembled with PL, and in order to preliminarily assess the pro-angiogenic potential of the nanocoatings, human umbilical vein ECs (HUVECs) adhesion, proliferation, morphology and gene expression were analyzed.

\section{Materials and methods}

\subsection{Materials}

Medium molecular weight chitosan (Chi), with a degree of deacetylation of 80\% (Sigma Aldrich, MKBB0566), was purified by a re-precipitation method. Briefly, Chi powder was dissolved in $2 \%(\mathrm{v} / \mathrm{v})$ acetic acid solution with $1 \%(\mathrm{w} / \mathrm{v})$ concentration. The mixture was stirred overnight at room temperature. The impurities were removed by four filtration cycles. Then, Chi was precipitated by addition of $1 \mathrm{M} \mathrm{NaOH}$ while stirring. Final steps consisted on washing Chi with distilled water until reaching a neutral $\mathrm{pH}$ and on Chi dehydration rising with ethanol-water mixtures with increasing ethanol content $(20-100 \% \mathrm{v} / \mathrm{v})$. Chi was freeze-dried for 3 days and ground. $\kappa$ - (Sigma-Aldrich, 22048), 1- (Fluka, 22045), $\lambda$-carrageenan (Car; Sigma-Aldrich, 22049), sodium heparin (Hep; Sigma-Aldrich, H3149), sodium alginate (Alg; Sigma Aldrich, $250 \mathrm{cP}$ ), and poly(ethyleneimine) solution (PEI; SigmaAldrich, P3143) were used as received.

\subsection{Materials preparation}

\subsubsection{Preparation of platelet lysate}

Platelet concentrates were obtained from different platelet collections performed at Instituto Português do Sangue (IPS, Porto, Portugal), under a previously established cooperation protocol. The components were obtained using the Trima Accel ${ }^{\circledR}$ Automated Blood Collection System. All the platelet products were biologically qualified according to the Portuguese legislation. The platelet count was performed at the IPS using the COULTER ${ }^{\circledR}$ LH 750 Hematology Analyzer and the sample volume adjusted to 1 million platelet $\mu \mathrm{L}^{-1}$. The collected samples were subject to three repeated temperature cycles (frozen with liquid nitrogen at $-196^{\circ} \mathrm{C}$ and heated at $37^{\circ} \mathrm{C}$ ) and frozen at $-20^{\circ} \mathrm{C}$ until further use. The remaining platelets were eliminated by centrifugation at

\section{Platelet Lysate}

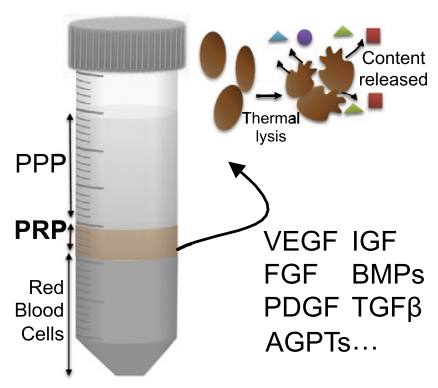

b Layer-by-Layer

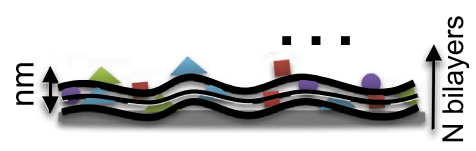

\section{Endothelial cell activation}
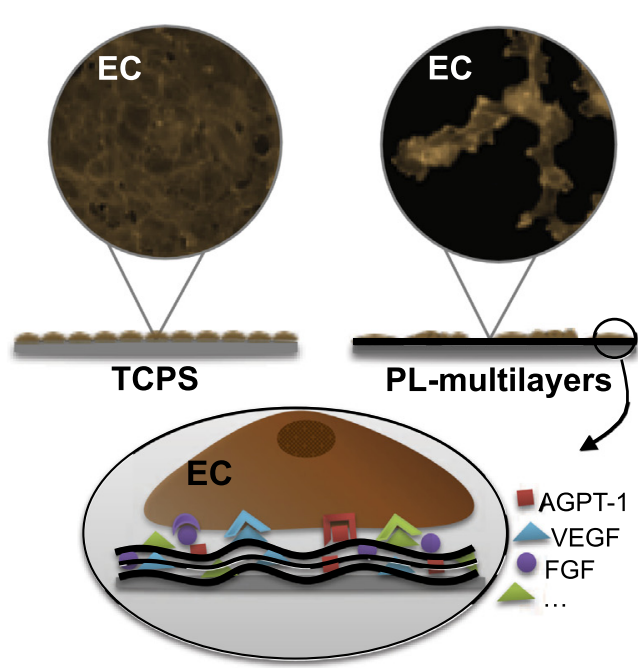

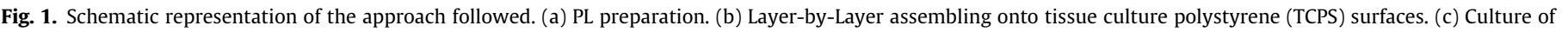
endothelial cells (ECs) during $20 \mathrm{~h}$ on the nanocoatings and expected interaction through VEGF, FGF, Angiopoietin-1 and other receptors. 
$1400 \mathrm{~g}$ for $10 \mathrm{~min}$. Aliquots of Platelet lysate (PL) were stored at $-20{ }^{\circ} \mathrm{C}$ until final use. This procedure has not jeopardized growth factors bioactivity [26].

\subsubsection{Polyelectrolytes solutions}

$\kappa-, 1-, \lambda$-Car, Hep and Alg were prepared in $1 \mathrm{M}$ Tris $\mathrm{HCl} 40 \mathrm{nM}$ $\mathrm{NaCl} \mathrm{pH} 7.4$ at a concentration of $0.5 \mathrm{mg} \mathrm{mL}^{-1}$. Chi was dissolved in sodium acetate buffer at a concentration of $0.5 \mathrm{mg} \mathrm{mL}^{-1}$. PL was 10 -fold diluted with Tris $\mathrm{HCl}$ buffer for the multilayers with Car, Hep and Alg, or with $1 \mathrm{M}$ sodium acetate $40 \mathrm{mM} \mathrm{NaCl} \mathrm{pH} 6$ to be combined with Chi.

\subsubsection{Coatings preparation in 48-well plates}

In order to prepare coatings with 6 bilayers of the pairs Alg/PL, Chi/PL, $\kappa$ Car/PL, ıCar/PL, $\lambda$ Car/PL and Hep/PL, all 48-well plates were modified with $0.5 \mathrm{~mL}$ of $0.5 \%(\mathrm{w} / \mathrm{v})$ PEI solution to confer a positive surface charge. Then, the solution was removed and the wells were extensively rinsed with distilled water in order to remove the unbound PEI. LbL assembling was started by the adsorption of the negative PE. In the case of Chi, an Alg layer was first adsorbed which was followed by Chi. The adsorption times and volumes used were: $4 \mathrm{~min}$ and $0.5 \mathrm{~mL}$ for the polysaccharides solutions; $0.5 \mathrm{~mL}$ and $10 \mathrm{~min}$ for the PL solution; intermediate rising steps $\mathrm{x} 2$ for $30 \mathrm{~s}$ using the respective buffers. The sequence was repeated 1,3 or 6 times. The well plates were let to air-dry overnight and then sterilized using a UV light for $40 \mathrm{~min}$.

\subsection{Cell behavior assessment}

\subsubsection{HUVECS isolation}

Human umbilical cords obtained after caesarean sections from healthy donors were provided by Hospital de S. Marcos, Braga, Portugal. They were delivered in transport buffer, containing $0.14 \mathrm{M}$ $\mathrm{NaCl}, 0.004 \mathrm{MKCl}$ and $0.011 \mathrm{M}$ glucose in $0.001 \mathrm{M}$ phosphate buffer at $\mathrm{pH}$ 7.4. Human umbilical cord vein endothelial cells (ECs) (HUVECS) were isolated as described in literature by Jaffe and others [1].

Biological samples were provided under a protocol approved by the Hospitals Ethical Committees and the 3B's Research Group. Cells were expanded using M199 supplemented with $50 \mu \mathrm{g} / \mathrm{mL}$ endothelial cell growth supplement (ECGS, BDBiosciences), $50 \mu \mathrm{g} / \mathrm{mL}$ of heparin, $3.4 \mu \mathrm{l} / \mathrm{mL}$ Gibco ${ }^{\circledR}$ GlutaMAX ${ }^{\mathrm{TM}}$ (Life Technologies) and 20\% fetal bovine serum (FBS). Cells were cultured at $37{ }^{\circ} \mathrm{C}, 5 \% \mathrm{CO}_{2}, 99 \%$ humidity and medium was exchanged every 2-3 days. HUVECs from two different donors and between passage 4 and 7 were used in the experiments.

\subsubsection{Cell culture}

To proceed with the cell seeding, expanded cells were harvested by trypsinization and filtered with a $100 \mu \mathrm{m}$ cell strainer to remove possible cell aggregates. Different cell densities were prepared: 20,000 cells $/ \mathrm{mL}$ with $0 \%$ FBS, 20,000 cells $/ \mathrm{mL}$ with $10 \%$ FBS, 20,000 cells/mL with $20 \%$ FBS for cell adhesion and proliferation quantification; 100,000 cells/mL, 200,000 cell $/ \mathrm{mL}$, 300,000 cells/mL with $10 \%$ FBS for cell morphology studies. A volume of $500 \mu \mathrm{L}$ of cell suspension was dispensed into each well. Well-plates were incubated for $20 \mathrm{~h}$. After that, medium was replaced with fresh one with $10 \%$ FBS, ECGS and sodium heparin for proliferation quantification. Medium without ECGS and sodium heparin was used as control.

For FGF/VEGF blockage test, M199 medium was supplemented with $10 \%$ FBS and DMSO or FGF/VEGF Receptor Tyrosine Kinase Inhibitor (PD173074, Santa Cruz Biotechnology), dissolved in DMSO. According with the manufacturer, it is (N-[2-[[4-(Diethylamino)butyl]amino]-6-(3,5-dimethoxyphenyl)pyrido[2,3-d]pyrimi-
din-7-yl]-N'-(1,1-dimethylethyl)urea) a potent inhibitor of many VEGF and FGF receptors.

HUVECs $\left(50,000\right.$ cells/500 uL) were seeded onto $1 \mathrm{~cm}^{2}$-coated well plates and cultured for $20 \mathrm{~h}$ in medium supplemented with $150 \mathrm{nM}(0.0075 \%$ in DMSO) or $200 \mathrm{nM}$ (0.01\% in DMSO) of inhibitor and only DMSO $(0.0075 \%$ and $0.01 \%)$.

\subsubsection{Cytoskeleton staining}

After $20 \mathrm{~h}$ or $4 \mathrm{~h}$ in culture, samples were gently rinsed twice with sterile PBS and then fixed with formalin $10 \%(\mathrm{v} / \mathrm{v})$ during $20 \mathrm{~min}$. Cells were permeabilized with $0.5 \mathrm{~mL}$ of Triton $0.2 \%(\mathrm{v} / \mathrm{v})$ in PBS during $2 \mathrm{~min}$ and then rinsed with PBS. Samples were incubated in the dark with $100 \mu \mathrm{L}$ of $(1: 100)$ Phalloidin-TRITC (Sigma-Aldrich) solution for $30 \mathrm{~min}$ and then washed with PBS. For cell nuclei staining, well plates were incubated in the dark for 5 min with $100 \mu \mathrm{L}$ 4,6-diamino-2-phenyindole dilactate (DAPI, Sigma-Aldrich) diluted 1:1000 in PBS. Samples were observed using an inverted Axio Observer Fluorescence Inverted Microscope (Zeiss, Germany) and random images recorded for analysis.

\subsection{Image analysis}

\subsubsection{Angiogenesis analyzer}

Angiogenesis Analyzer, a toolset of Image J software, allowed the analysis of cellular networks.

The total length of the tube-like structures, number of nodes and of master nodes, number of meshes and of master meshes were quantified on cytoskeleton fluorescence images of HUVECs after $20 \mathrm{~h}$ of culture. A node was defined as pixels that have at least 3 neighbors, corresponding to a bifurcation. A junction was considered a node or fused nodes. The segments correspond to elements that were limited by two junctions/nodes while the branches were elements delimited by a junction and one extremity. The master segments were considered pieces of three, delimited by two junctions, but not exclusively implicated with one branch (master junctions). The master junctions linked at least 3 master segments. The meshes were defined as areas enclosed by the segments or master segments.

\subsubsection{Cell profiler}

Cell Profiler [43] allowed analysing the morphological changes of HUVECs when cultured for $20 \mathrm{~h}$ on coatings, in the presence or absence of inhibitors. was Eccentricity, form factor and major and minor axis length features available with Cell Profiler analysis were used. The values of eccentricity is defined as the ratio of the distance between the foci of the considered ellipse and its major axis length. The values vary between 0 and 1 . Values equal to zero are actually circles while ellipses with eccentricity of 1 are lines. The form factor was calculate as $4 \pi$ (Cell Area)/(Cell Perimeter)2, where 1 represent a perfect circular cell. The major and minor axis length (in pixels) correspond to the major and minor axis of the ellipse, respectively. The images used for Cell Profiler analyses were the same as for Angiogenesis Analyzer.

\section{5. dsDNA quantification}

In order to quantify cell attachment after $20 \mathrm{~h}$ and proliferation up to 4 days in culture, dsDNA was quantified using the Quant-iT ${ }^{\mathrm{TM}}$ PicoGreen ${ }^{\circledR}$ dsDNA assay kit (Molecular Probes/Invitrogen) following the manufacturer instructions. After the incubation periods, the well plates were gently rinsed once with sterile PBS. Then, $1 \mathrm{~mL}$ of ultra-pure sterile water added and kept at $-80^{\circ} \mathrm{C}$ until quantification. For the quantification, samples were defrosted at room temperature and the fluorescence was read in a microplate reader at an excitation wavelength of $485 \mathrm{~nm}$ and emission wavelength of $528 \mathrm{~nm}$. A standard curve was created by varying 
the concentration of standard dsDNA standard from 0 to $2 \mathrm{mg} \mathrm{mL}^{-1}$. dsDNA values of the samples were read off from the standard graph. At least five specimens were measured per each sample.

\subsection{Real time $R T-P C R$}

The quantification of angiogenic gene expression (Table 1 ) of the HUVECS cultured on the coatings and on TPCS during $20 \mathrm{~h}$, was performed using quantitative PCR by a two-step fluorogenic assay using the PerfeCta ${ }^{\mathrm{TM}} \mathrm{SYBR}^{\circledR}$ Green System (Quanta Biosciences).

The total RNA was extracted using the TRI ${ }^{\circledR}$ Reagent (Sigma-Aldrich), following the manufacturer's instructions and then quantified using Nanodrop ${ }^{\circledR}$ ND-100 spectrophotometer (thermo Scientific). First-strand complementary DNA (cDNA) was synthetized using $1 \mu \mathrm{g}$ RNA of each sample and the qScriptTM cDNA Synthesis Kit (Quanta Biosciences) for a $20 \mu \mathrm{L}$ reaction. The obtained cDNA was used as a template for the amplification of the target genes using a MasterCycler EP Gradient detection System (Eppendorf) thermocycler and the PerfeCtaTM SYBR ${ }^{\circledR}$ Green System kit following the manufacturers' instructions. The Livak method, $2^{-\Delta \Delta \mathrm{Ct}}$, was used to evaluate the relative expression of each target gene. $\Delta \mathrm{Ct}$ was calculated by the difference between the $\mathrm{Ct}$ values of the target gene and the $\beta$-actin or GAPDH endogenous housekeeping gene. $\Delta \Delta \mathrm{Ct}$ was obtained by subtracting the $\Delta \mathrm{Ct}$ of the calibrator sample (TCPS) to the $\Delta \mathrm{Ct}$ of the sample. The results are represented as $2^{-\Delta \Delta C t}$ and as gene expression relative to TCPS.

\subsection{Statistical analysis}

The normality of the data was verified with Shapiro-Wilk test. All data was then statistically analyzed using non-parametric tests. The unpaired one-tailed $t$-test with Welch's correction for nonparametric data was used $(p \leqslant 0.05)$.

\section{Results and discussion}

In the natural ECM, glycosaminoglycans presenting various molecular arrangements, as well as different sulfation degrees (SD), bind and stabilize GFs mainly by electrostatic interactions [27-29]. Heparin, or synthetic heparin-analogue ending sulfate groups, are widely used to stabilize and attract GFs [30-31]. Since they present high affinity and the interactions are mainly electrostatic, the conformation and bioactivity of the GFs is usually preserved. Natural resources, including those from marine-origin, offer a wide range of PEs with several molecular properties and SD that may affect the incorporation of GFs from PL onto the coatings [32-34]. Therefore, marine-origin polysaccharides were

Table 1

Sequences and melting temperature of the angiogenic genes analyzed.

\begin{tabular}{|c|c|c|}
\hline Gene & Primer sequence (Forward, Reverse $5^{\prime}-3^{\prime}$ ) & $\operatorname{Tm}\left({ }^{\circ} \mathrm{C}\right)$ \\
\hline \multirow[t]{2}{*}{$\beta$-actin } & ACTGGAACGGTGAAGGTGAC & 59.5 \\
\hline & AGAGAAGTGGGGTGGCTTTT & \\
\hline \multirow[t]{2}{*}{ GAPDH } & ACAGTCAGCCGCATC & 58.4 \\
\hline & GACAAGCTTCCCGTTCTCAG & \\
\hline \multirow[t]{2}{*}{ Integrin $\beta 3$} & ACCAGTAACCTGCGGATTGG & 59.4 \\
\hline & TCCGTGACACACTCTGCTTC & \\
\hline \multirow[t]{2}{*}{ Integrin $\alpha \nu$} & CCGATTCCAAACTGGGAGCA & 59.4 \\
\hline & GGCCACTGAAGATGGAGCAT & \\
\hline \multirow[t]{2}{*}{ Integrin $\propto 5$} & TGGCCTTCGGTTTACAGTCC & 59.4 \\
\hline & GGAGAGCCGAAAGGAAACCA & \\
\hline \multirow[t]{2}{*}{ VEGFA } & GACAGATCACAGGTACAGGG & 58.4 \\
\hline & AGAAGCAGGTGAGAGTAAGC & \\
\hline \multirow[t]{2}{*}{$\mathrm{FGFb}$} & GAGCAAATCTGCCCTGCTCA & 59.4 \\
\hline & TCCCGCATACTCTGGAGACA & \\
\hline \multirow[t]{2}{*}{ Angiopoietin-1 } & GAAGGGAACCGAGCCTATTC & 58.4 \\
\hline & GGGCACATTTGCACATACAG & \\
\hline
\end{tabular}

considered convenient and cost-effective sources of PEs to attract, stabilize, buildup and tune PL nanocoatings prepared by LbL assembling [35]. We hypothesize that such combination of PEs and PL could be an adequate strategy to deconstruct fundamental structural and functional aspects of the extra-cellular matrix towards the design of clinically relevant tissue engineering constructs able to stimulate angiogenesis [36]. PEs with different charge and functional groups were combined with PL, namely: alginate (Alg; -1 ) and chitosan ( $\mathrm{Chi} ;+1)$, as non-sulfated PEs; and $\kappa-, 1-$, and $\lambda$-carrageenan ( $\kappa$ Car, 1 Car, $\lambda$ Car; $-1,-2,-3$ respectively), as sulfated PEs; along with heparin (Hep; -3 ), as a control sulfated PE. In a previous work [26], the capability of these PEs to sequester fibroblast growth factor $b$ (FGFb), vascular endothelial growth factor A (VEGF A) and platelet derived growth factor (PDGF) from PL during the assembling was analyzed. It has been observed that the content of those GFs in the nanocoatings (30-50 thick with 6 bilayers) was highly influenced by the nature of the PE. Briefly, the sulfated PEs and Hep were able to adsorbed higher levels of GFs; however, higher SD did not imply enhanced incorporation. Namely, PDGF adsorption was decreased with the increase of SD, while the highest contents of VEGF A reached were detected on Hep and 1 Car. Interestingly, ıCar was able to adsorb a high amount of all the measured GFs. Consequently, higher SD represented nanocoatings with increased VEGF A/PDGF and $\mathrm{FGFb} / \mathrm{PDGF}$ ratios suggesting them to be more adequate for the morphogenic activation of EC.

\subsection{Endothelial cells adhesion}

The HUVECs were seeded onto coatings of PL with 6 bilayers of Alg/PL, Chi/PL, $\kappa$ Car/PL, 1 Car/PL, $\lambda$ Car/PL and Hep/PL, in the absence of both EC growth supplement (ECGS) and Hep, and with varied concentrations of fetal bovine serum (FBS, $0 \%, 10 \%$ and $20 \%$ ) up to $20 \mathrm{~h}$ - Fig. $2 \mathrm{a}$.

In absence of serum, the adhesion of HUVECs was limited and the number of cells in all the coatings and in the tissue culture polystyrene (TCPS) was similar - Fig. 2a. Comparing to TCPS, with $10 \%$ FBS, cell adhesion was not significantly affected by the presence of the multilayers with exception of Alg and Chi $(p<0.05)$ - Fig. 2b. Increasing the content of FBS to $20 \%$ has also not altered much the adhesion of HUVECS relatively to TCPS - Fig. 2c. Nonetheless, in presence of serum, HUVECS tended to adhere more on ${ }_{1} \mathrm{Car} / \mathrm{PL}_{6}(p<0.05)$. On the other hand, the Chi/PL and Alg/PL nanocoatings showed a tendency to impair cell adhesion $(p<0.05)$, independently on the concentration of FBS.

\subsection{Endothelial cells morphology}

The ability of those multilayers to activate ECs towards the formation of tube-like structures (TLS) was also assessed. HUVECs were seeded with a density of 100,000 cells $/ \mathrm{cm}^{2}$ in presence of $10 \%$ FBS and their morphology was observed after $20 \mathrm{~h}$ of incubation. Fig. 3 and Fig. S1 show the HUVECs morphology on all the assessed conditions. $\lambda / \mathrm{PL}_{6}$ and $\mathrm{Hep} / \mathrm{PL}_{6}$ induced considerably higher cell cohesion, forming branching anastomosing tubes-like with multicentric junctions giving rise to a network of TLS Fig. 4. No clear TLS were observed in $\mathrm{Alg} / \mathrm{PL}_{6}, \mathrm{Chi} / \mathrm{PL}_{6}$ nor $\mathrm{t} / \mathrm{PL}_{6}$. Although Chi and Alg PEs significantly adsorb PL [26], the nature or stability of their pro-angiogenic cues were not enough to induce the cellular assembling. In the case of $\mathrm{v} / \mathrm{PL}$, TLS structures were observed under other cell density conditions $\left(53,000\right.$ cells $\left./ \mathrm{cm}^{2}\right)-$ Fig. S2. The ECs highly adhered onto $1 / \mathrm{PL}_{6}$, which is believed to consequently inhibit TLS formation. This might be caused by VE cadherin complexation with VEGF receptor, which inhibits its phosphorylation by VEGF and consequently the formation of TLS [37]. 

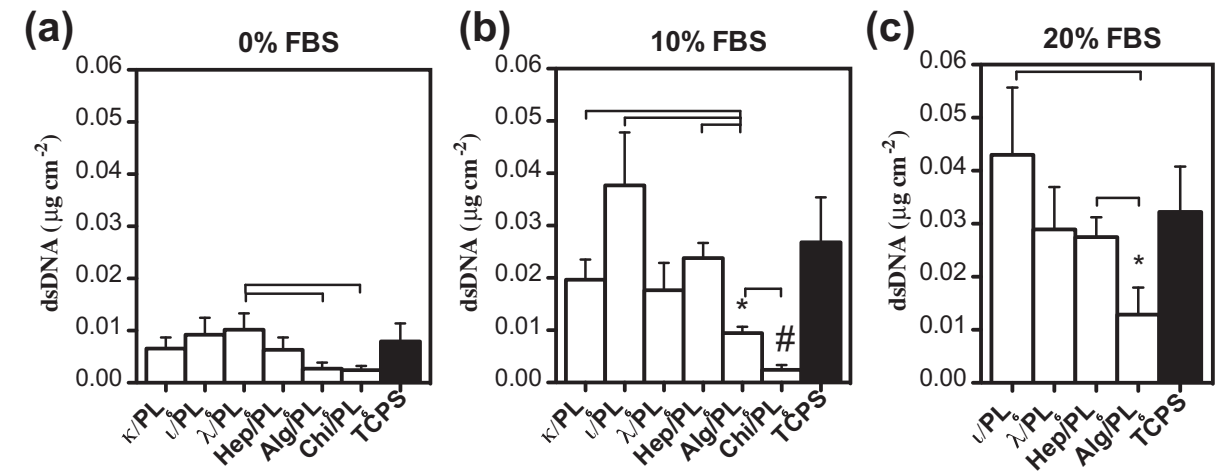

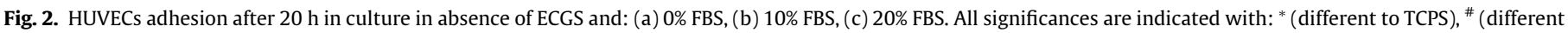
to all) and bars (pair is different), ( $p<0.05, n=6$; mean \pm sem).

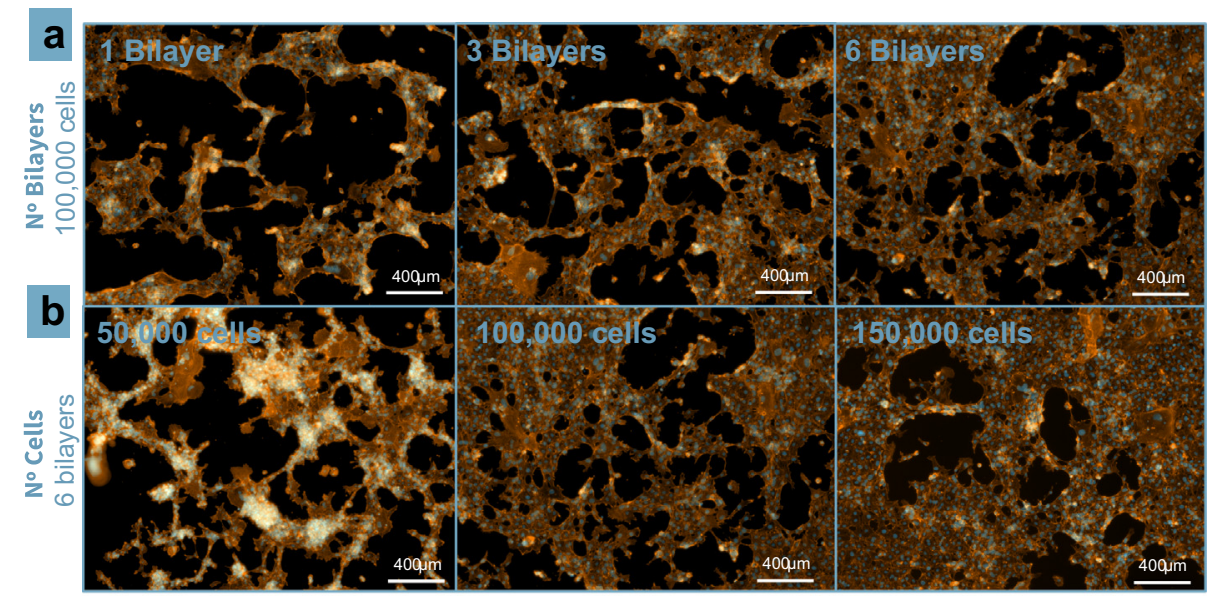

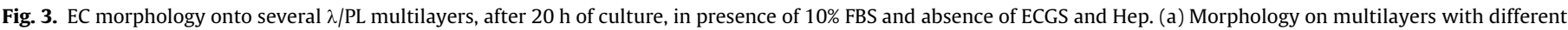

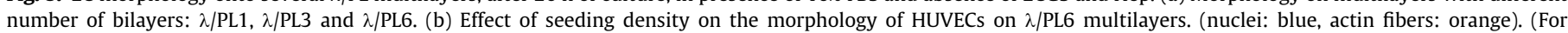
interpretation of the references to colour in this figure legend, the reader is referred to the web version of this article.)

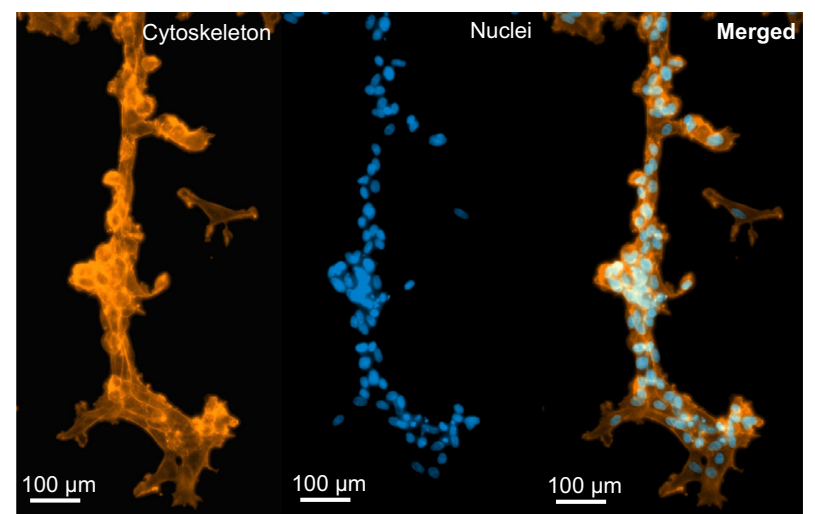

Fig. 4. Representative image of HUVECS assembled into a tube-like structure after $20 \mathrm{~h}$ in culture (nuclei: blue, actin fibers: orange). (For interpretation of the references to colour in this figure legend, the reader is referred to the web version of this article.)

The number of bilayers forming the nanocoatings could also affect the density of instructive proteins presented to the cells. Thereby, the cell seeding density of HUVECs and the number of bilayers of the $\lambda / \mathrm{PL}$ pair were also varied. Respectively, 50,000, 100,000 and 150,000 cells $/ \mathrm{cm}^{2}$ were seeded on $\lambda / \mathrm{PL}_{6}$, and 100,000 cells $/ \mathrm{cm}^{2}$ seeded on nanocoatings prepared with 1,3 and 6 bilayers $\left(\lambda / \mathrm{PL}_{1}, \lambda / \mathrm{PL}_{3}\right.$ and $\left.\lambda / \mathrm{PL}_{6}\right)-$ Fig. 3. Total tube-length, number of meshes, number of nodes and master junctions formed were quantified on fluorescence images $(5 \times)$ using Angiogenesis Analyzer for Image $\mathrm{J}-$ Fig. 5. A single bilayer of $\lambda / \mathrm{PL}$ was sufficient to promote the formation of a network with 100,000 cells, which total tube length could be increased with increasing number of layers. With 6 bilayers, a lower cell density has shown to be more adequate in obtaining a better network formation than with fewer layers. This indicates that cell adhesion and TLS are dependent on the number of bilayers and increasing the number of layers allows a decrease of the required cell density.

Besides the total tube length, the number of nodes and meshes were also influenced by the number of layers. It was observed a tendency of increase all the features with the increasing of the number of layers. In general, $\mathrm{Hep} / \mathrm{PL}_{6}(100,000$ cells $)$ and $\lambda / \mathrm{PL}_{6}$ $(50,000$ cells $)$ have shown similar results, though a higher number of total nodes was observed on $\lambda$ Car.

Cell Profiler was used to analyze cell form factor (i.e., roundness), eccentricity (i.e., elongation), major axis (i.e., cell length) and minor axis (i.e., cell width) - Fig. S3. This analysis revealed that under the tested conditions, the EC morphology was significantly changed when seeded on the multilayers in comparison to TCPS. While on TCPS cells show the normal cobblestone-like morphology, they become rounder on the instructive multilayers (form factor closer to 1). However, on the multilayers that successfully induced TLS, the cells elongation factor was similar to TCPS. Both width and length decreased on the multilayers, thus not altering significantly the elongation relatively to TCPS. 
(a)

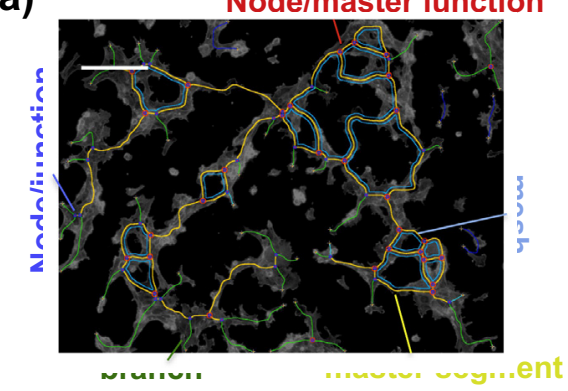

(c)

(e)
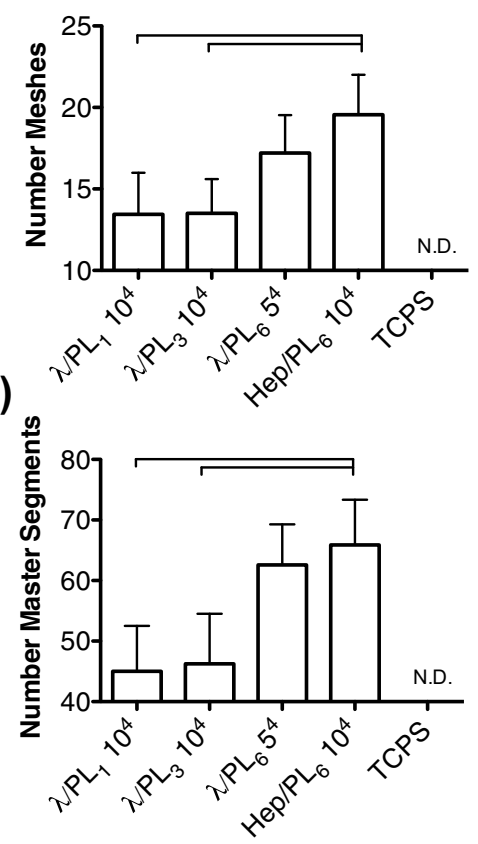

(b)

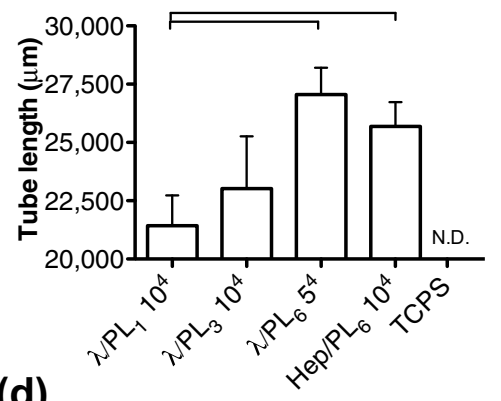

(d)

(f)
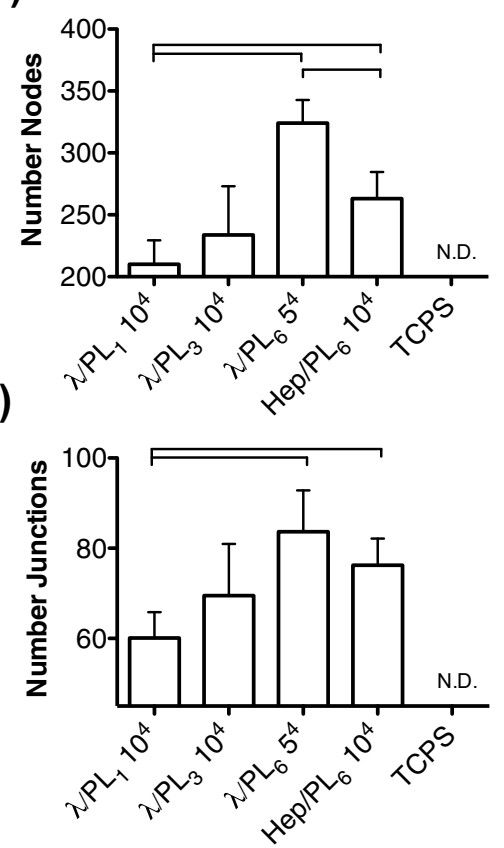

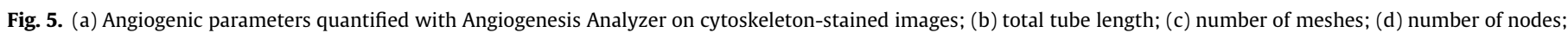

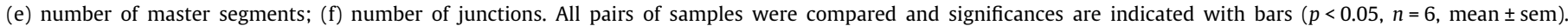
$5^{4}=50,000$ cells $/ \mathrm{cm}^{2} ; 10^{4}=100,000$ cells $/ \mathrm{cm}^{2} ; 15^{4}=150,000$ cells $/ \mathrm{cm}^{2}$.

Frequently, on hydrogel-like basement membranes, cells tend to be more elongated after 20-24 h of incubation. [38] Herein, the surface properties (non-gel), the time of incubation and the cell number may have caused the reduction of the size and the lack of cytoskeleton elongation.

\subsection{Endothelial cells proliferation}

In order to assess cell proliferation capability, the medium was replaced with fresh medium with or without ECGS-Hep and cells were incubated for more 3 days - Fig. 6a and b. Morphology was observed after 4 days in culture - Fig. 6c. Even though the initial media was changed, removing possible released GFs, HUVECs kept some cell alignment after 4 days in culture on $\lambda \mathrm{PL}_{6}$ $\left(50,000\right.$ cells $\left./ \mathrm{cm}^{2}\right)$. On the other hand, in presence of ECGS cells have lost the TLS and reached confluence.

Independently of the surface, in absence of growth supplement, cells were unable to proliferate. In particular, $\mathrm{Hep} / \mathrm{PL}_{6}$ has not supported cell viability, and cell number was slightly reduced $(p<0.05)$ which suggests a lower pro-survival stimulation.

Medium supplementation with ECGS allowed a minimal proliferation of the ECs, being this effect more pronounced on TCPS $(p<0.05)$. Among the multilayers, $1 / \mathrm{PL}_{6}$ showed the highest
HUVECs proliferation. This improvement might be related with the higher capability of ${ }_{1}$ Car to incorporate FGFb, which growth factor is reported to be able of stimulating EC proliferation [39]. Nonetheless, the overall behavior suggested that these multilayers do not promote ECs proliferation, and TLS formation in some cases. This corroborates the reported tendency of matrices that lead to extensive tubule formation (e.g., collagen IV, V and Matrigel) of allowing only a minimal EC proliferation $[6,40]$. This proliferation inhibition effect could be promoted by specific GFs that are simultaneously capable of eliciting the formation of TLS and inhibit EC proliferation. For instance, transforming growth factor beta 1 (TGF- $\beta 1$ ) induces angiogenesis through VEGF A-mediated apoptosis [41]. TGF- $\beta 1$ is one of the multiple GF that can be found in PL. The simultaneous presence of TGF- $\beta 1$ and other GFs, rather than only promoting angiogenesis or mitogenesis (e.g., by FGFb and VEGF A, PDGF), could both elicit angiogenesis and impair proliferation or cell apoptosis.

\subsection{Angiogenic-gene expression}

During the angiogenesis stages (activation, proliferation, migration and stabilization) the gene expression of the ECs is regulated by several pro and anti-angiogenic factors. GFs such as VEGF $A$ 
(a)

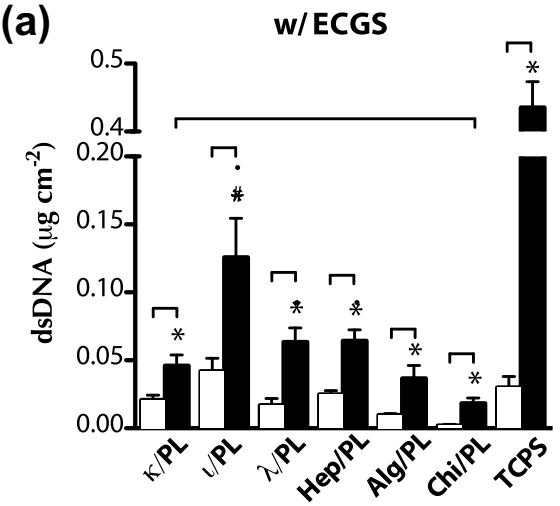

(b)

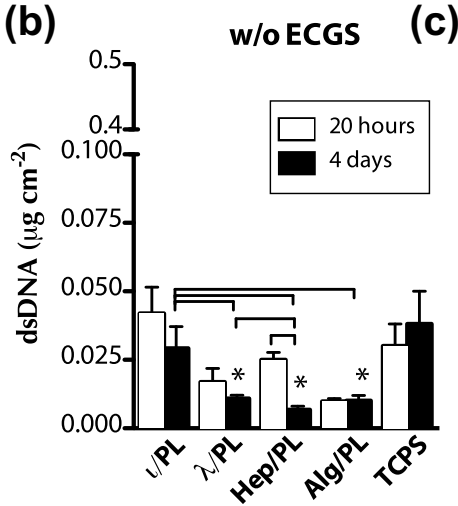

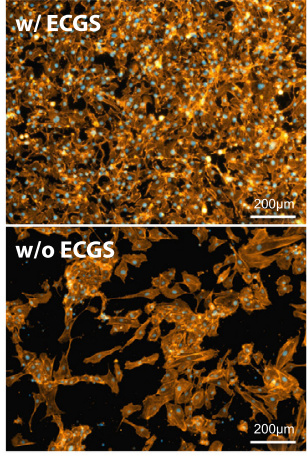

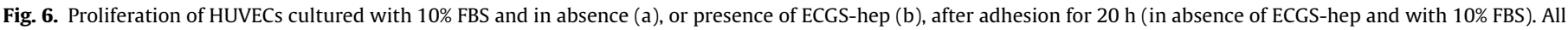

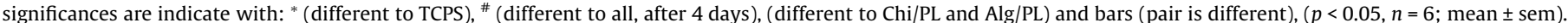

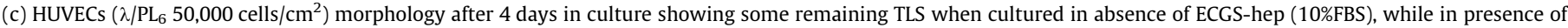
ECGS-hep (10\%FBS) cells had disassembled, proliferated and reached confluence.

and FGFb activate ECs and promote their proliferation. Integrin such as $\alpha 5, \alpha v, \beta 3$ play important roles during EC migration while angiopoietin-1, PDGF and TGF- $\beta$ regulate maturation and vessels stabilization $[8,42,43]$. Herein, gene expression of VEGFA, FGFb, integrins ( $\alpha 5, \alpha \nu$ and $\beta 3$ ) and angiopoietin-1 were quantified after 20 h of culture - Fig. 7.

In accordance with the literature, the angiogenic-gene expression alterations during TLS formation are expected to be of small magnitude (<2-fold) or even negative, as related to TCPS $[42,44]$. Indeed, for the majority of conditions, gene expression was similar or significantly lower than TCPS with the exception of the expression of VEGFA and angiopoietin-1. Regarding the expression of integrins, $\lambda / \mathrm{PL}_{6} \quad(50,000$ cells $), \lambda / \mathrm{PL}_{3} \quad(100,000$ cells $), \quad 1 / \mathrm{PL}_{6}$ (100,000 cells) and Hep/PL 6 (100,000 cells) have, in general, shown lower or similar expression to TCPS $(p<0.05)$. Exogenous FGFb is known to be able to promote angiogenesis, both in vivo and in vitro, by up-regulating the expression of VEGFA and the endogenous VEGFA in ECs [45]. However, the expression of FGFb was decreased on $1 / \mathrm{PL}_{6}\left(100,000\right.$ cells), $\lambda / \mathrm{PL}_{3}$ (100,000 cells), $\lambda / \mathrm{PL}_{6}$ (50,000 cells), $\lambda / \mathrm{PL}_{6}$ (100,000 cells), with exception of $\mathrm{Hep} / \mathrm{PL}_{6}$.
Both VEGFA and angiopoietin-1 are strong pro-angiogenic factors with distinct functions and bidirectional dependent: one up-regulates the other. While VEGFA causes vascular permeability, angiopoietin-1 stabilizes the blood vessels and avoids plasma leakage induced by VEGFA $[46,47]$. Although being frequently related with different angiogenesis stages, the simultaneously stimulation of ECs with VEGFA and angiopoietin-1 has previously shown a synergistic improvement of angiogenesis [48].

Recently, it has been reported that PRP contains high amounts of angiopoietin-1 ( 300 fold more than VEGFA) [16]. The same study has shown that angiopoietin-1 and its respective cell receptor (Tie2) are crucial in promoting angiogenesis when using a preparation of 250-fold diluted PRP.

Both the expression of VEGF $A$ and angiopoietin-1 were simultaneously increased with exception of TCPS, $\mathrm{Alg} / \mathrm{PL}_{6}$ and $\mathrm{i} /$ $\mathrm{PL}_{6}$. Angiopoietin-1 was increased even on the multilayers not promoting TLS which suggests that surface VEGFA or FGFb (which primarily up-regulates VEGFA [45]) might have up-regulated angiopoietin-1 [49]. If a significant amount of angiopoietin-1 had been incorporated in the coatings, this could up-regulate VEGFA
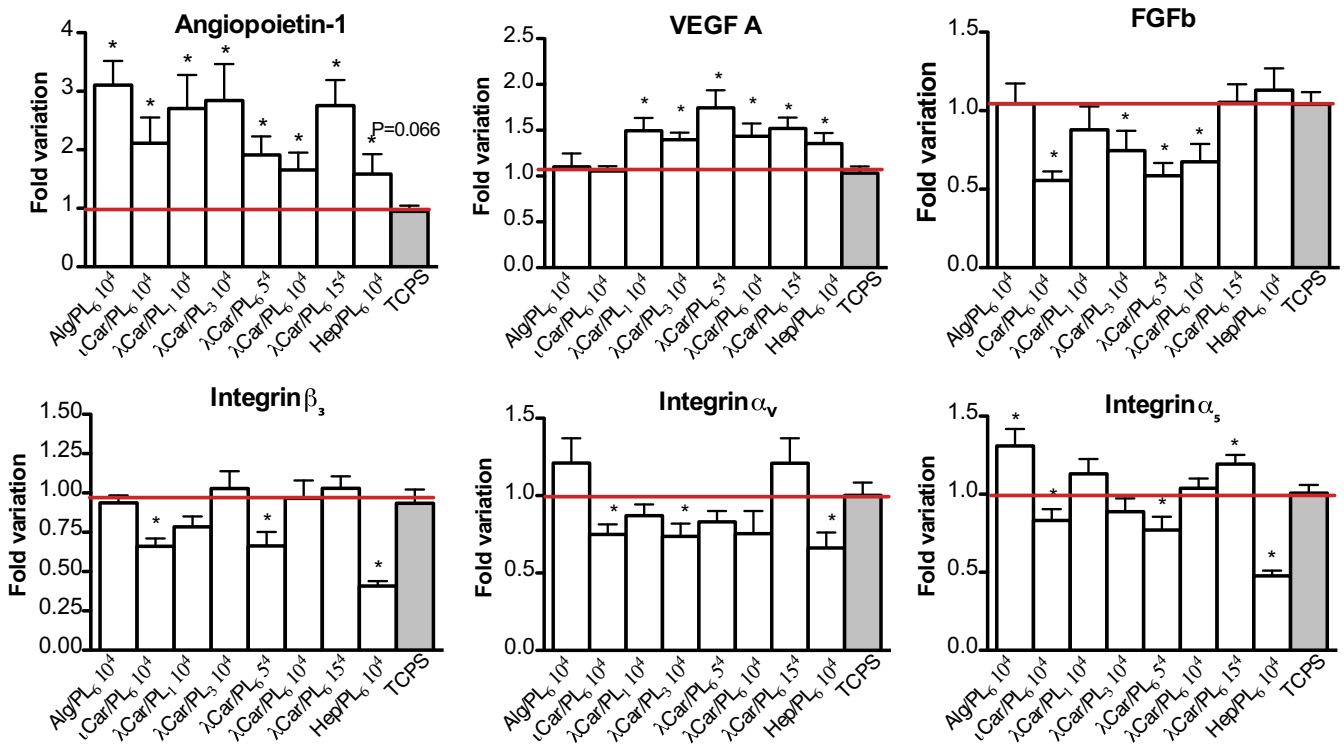

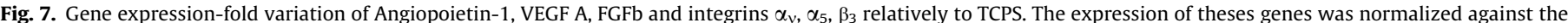

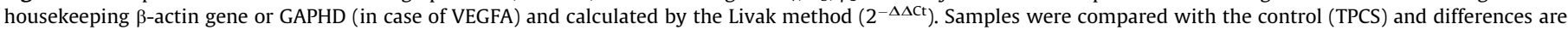
identified with ${ }^{*}(p<0.05, n=8$, mean \pm sem $)$. 


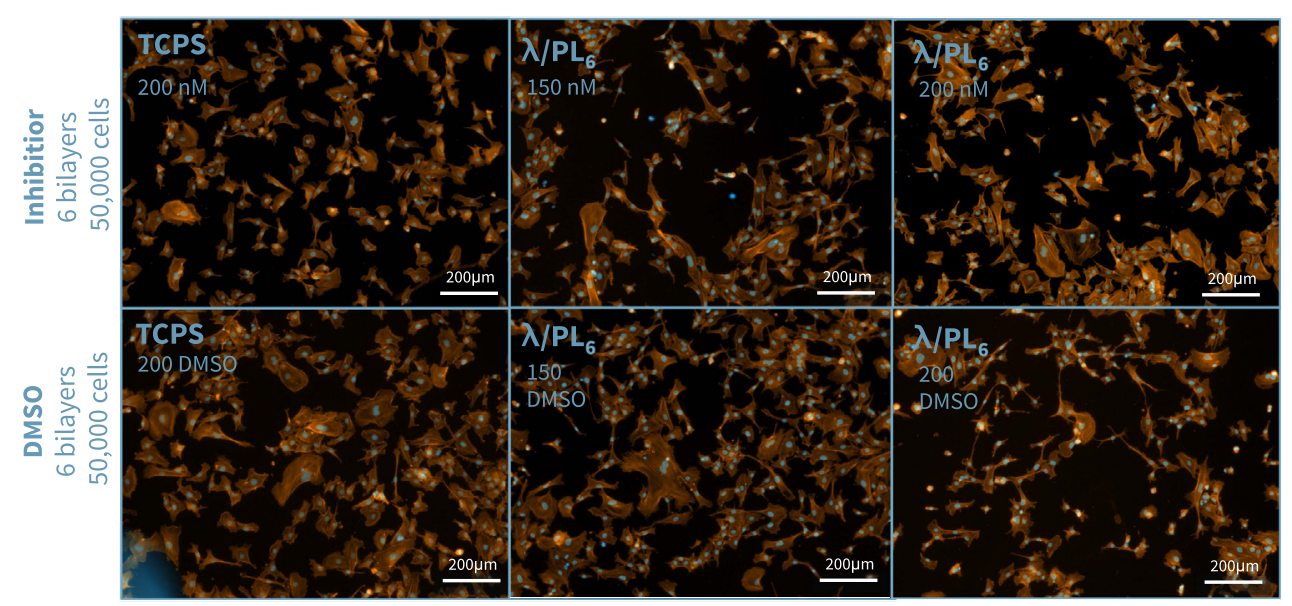

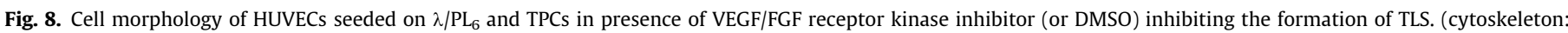
orange; nuclei: blue). (For interpretation of the references to colour in this figure legend, the reader is referred to the web version of this article.)

expression and VEGFA endogenous content, and consequently, indirectly stimulate the formation of TLS $[48,50,51]$.

\subsection{Blockage of FGF/VEGF tyrosine kinase receptor}

HUVECs were cultured in the presence of a FGF/VEGF tyrosine kinase receptor inhibitor to understand whether the morphogenic changes were driven by those pro-angiogenic GFs. This compound could block the interaction of FGF and VEGF from the nanocoating, or the soluble form, with their respective cell receptors (e.g., FGFR2 and VEGFR2). A condition that was shown to induce TLS was selected: 50,000 cells $/ \mathrm{cm}^{2}$ onto $\lambda / \mathrm{PL}_{6}$. Cells were seeded with a supplier's recommended range of concentrations of inhibitor dissolved with DMSO (150 nM and $200 \mathrm{nM}$, containing $0.0075 \% \mathrm{v} / \mathrm{v}$ and $0.01 \% \mathrm{v} / \mathrm{v}$ DMSO, respectively) or only with DMSO $(0.0075 \%$ $\mathrm{v} / \mathrm{v}$ and $0.01 \% \mathrm{v} / \mathrm{v}$ of DMSO - named DMSO 150 and DMSO 200) during $20 \mathrm{~h}$. The use of DMSO as a solvent has diminished the observed cellular density and made cells more elongated - Fig. 8. However, the ability of HUVECS to be more cohesive and to align was further reduced with the presence of the inhibitor and with its increased concentration. No TLS were observed on the surfaces. Cell Profiler analysis has not revealed significant cell shape differences between $\lambda / \mathrm{PL}_{6}(50,000$ cells $)$ with inhibitor and only with DMSO, both for $150 \mathrm{nM}$ and for $200 \mathrm{nM}$ - Fig. S3. DMSO is reported as being able to decrease cell adhesion even at low concentrations $(1.55 \% \mathrm{v} / \mathrm{v})$ [52]. Concentrations higher than $1 \% \mathrm{v} / \mathrm{v}$ have also been reported to impair the formation of TLS on Matrigel [53]. Thereby, one cannot exclude the inhibition of TLS and changes in cell morphology to be in part caused by DMSO. Nonetheless, there are indications that at least at some extent, FGF/VEGF has mediated the formation of TLS.

The PL coatings assembled with the more sulfated polysaccharides were able to induce a pro-angiogenic profile in HUVECs. This strategy may be a cost-effective way to introduce pro-angiogenic interfaces on surfaces or 3D scaffolds.

\section{Conclusions}

There is still a current need to develop cost effective cellinterfaces able to promote angiogenesis and the formation of stable vasculature.

PL is a source of several pro-angiogenic and other proteins involved in the angiogenesis from the earliest to the maturation phases. Herein, PL was incorporated in layer-by-layer assembled nanocoatings with varied polysaccharides and number of layers.
The nanocoatings prepared with the more sulfated polysaccharides elicited the formation of tube-like structures in ECs within $20 \mathrm{~h}$ of incubation. These morphogenic changes were accompanied by differences in gene expressions, mainly higher VEGFA and higher angiopoietin-1. Future work must be performed in order to clarify the rule of PL as well as the in vivo behavior of the developed structures.

Layer-by-Layer assembling including PL might be a simple methodology to introduce and tune cost-effective pro-angiogenic interfaces in 2D/3D biomaterials.

\section{Acknowledgments}

The research leading to these results has received funding from European Union's Seventh Framework Program (FP7/2007-2013) under grant agreement $\mathrm{n}^{\mathrm{a}}$ REGPOT-CT2012-316331 - POLARIS and FP7-KBBE-2010-4-266033 - SPECIAL. This work was also supported by the European Research Council grant agreement ERC-2012-ADG-20120216-321266 for the project ComplexiTE. Portuguese Foundation for Science and Technology is gratefully acknowledged for fellowship of Sara M. Oliveira (SFRH/BD/70107 /2010). The researcher contract of R.P. Pirraco through RL3-TECTNORTE-01-0124-FEDER-000020, co-financed by North Portugal Regional Operational Program (ON.2-O Novo Norte), under the National Strategic Reference Framework, through the European Regional Development Fund is also acknowledged.

\section{Appendix A. Supplementary data}

Supplementary data associated with this article can be found, in the online version, at http://dx.doi.org/10.1016/j.actbio.2015.12. 028.

\section{References}

[1] F.A. Auger, L. Gibot, D. Lacroix, The pivotal role of vascularization in tissue engineering, Annu. Rev. Biomed. Eng. 15 (2013) 177-200.

[2] E.C. Novosel, C. Kleinhans, P.J. Kluger, Vascularization is the key challenge in tissue engineering, Adv. Drug Delivery Rev. 63 (2011) 300-311.

[3] M.I. Santos, R.L. Reis, Vascularization in bone tissue engineering: physiology, current strategies, major hurdles and future challenges, Macromol. Biosci. 10 (2010) 12-27.

[4] Y.J. Blinder, D.J. Mooney, S. Levenberg, Engineering approaches for inducing blood vessel formation, Curr. Opin. Chem. Eng. 3 (2014) 56-61.

[5] L.E. Bertassoni, M. Cecconi, V. Manoharan, M. Nikkhah, J. Hjortnaes, A.L. Cristino, G. Barabaschi, D. Demarchi, M.R. Dokmeci, Y. Yang, A. Khademhosseini, Hydrogel bioprinted microchannel networks for vascularization of tissue engineering constructs, Lab Chip 14 (2014) 2202-2211. 
[6] C.A. Staton, M.W. Reed, N.J. Brown, A critical analysis of current in vitro and in vivo angiogenesis assays, Int. J. Exp. Pathol. 90 (2009) 195-221.

[7] M.W. Irvin, A. Zijlstra, J.P. Wikswo, A. Pozzi, Techniques and assays for the study of angiogenesis, Exp. Biol. Med. (Maywood) 239 (2014) 1476-1488.

[8] X.M. van Wijk, T.H. van Kuppevelt, Heparan sulfate in angiogenesis: a target for therapy, Angiogenesis 17 (2014) 443-462.

[9] M. Matsui, Y. Tabata, Enhanced angiogenesis by multiple release of plateletrich plasma contents and basic fibroblast growth factor from gelatin hydrogels, Acta Biomater. 8 (2012) 1792-1801.

[10] G. Sufen, Y. Xianghong, C. Yongxia, P. Qian, bFGF and PDGF-BB have a synergistic effect on the proliferation, migration and VEGF release of endothelial progenitor cells, Cell Biol. Int. 35 (2011) 545-551.

[11] G. Sun, Y.I. Shen, S. Kusuma, K. Fox-Talbot, C.J. Steenbergen, S. Gerecht, Functional neovascularization of biodegradable dextran hydrogels with multiple angiogenic growth factors, Biomaterials 32 (2011) 95-106.

[12] Q. Sun, E.A. Silva, A. Wang, J.C. Fritton, D.J. Mooney, M.B. Schaffler, P.M. Grossman, S. Rajagopalan, Sustained release of multiple growth factors from injectable polymeric system as a novel therapeutic approach towards angiogenesis, Pharm. Res. 27 (2010) 264-271.

[13] K. Stellos, S. Kopf, A. Paul, J.U. Marquardt, M. Gawaz, J. Huard, H.F. Langer, Platelets in Regeneration. Seminars in Thrombosis and Hemostasis, Thieme Medical Publishers, 2010. p. 175-84.

[14] S.C. Bir, J. Esaki, A. Marui, K. Yamahara, H. Tsubota, T. Ikeda, R. Sakata, Angiogenic properties of sustained release platelet-rich plasma: characterization in-vitro and in the ischemic hind limb of the mouse, J. Vasc Surg. 50 (2009) 870-879. e2.

[15] N. Kakudo, N. Morimoto, S. Kushida, T. Ogawa, K. Kusumoto, Platelet-rich plasma releasate promotes angiogenesis in vitro and in vivo, Med. Mol Morphol. 47 (2014) 83-89.

[16] T. Mammoto, A. Jiang, E. Jiang, A. Mammoto, Platelet rich plasma extract promotes angiogenesis through the angiopoietin1-Tie2 pathway, Microvasc. Res. 89 (2013) 15-24.

[17] B. Zhou, J. Ren, C. Ding, Y. Wu, D. Hu, G. Gu, J. Li, Rapidly in situ forming platelet-rich plasma gel enhances angiogenic responses and augments early wound healing after open abdomen, Gastroenterol. Res. Pract. 2013 (2013). 926764.

[18] Y. Man, P. Wang, Y. Guo, L. Xiang, Y. Yang, Y. Qu, P. Gong, L. Deng, Angiogenic and osteogenic potential of platelet-rich plasma and adipose-derived stem cell laden alginate microspheres, Biomaterials 33 (2012) 8802-8811.

[19] F. Findikcioglu, K. Findikcioglu, R. Yavuzer, N. Lortlar, K. Atabay, Effect of preoperative subcutaneous platelet-rich plasma and fibrin glue application on skin flap survival, Aesthetic Plast. Surg. 36 (2012) 1246-1253.

[20] J. Leotot, L. Coquelin, G. Bodivit, P. Bierling, P. Hernigou, H. Rouard, N. Chevallier, Platelet lysate coating on scaffolds directly and indirectly enhances cell migration, improving bone and blood vessel formation, Acta Biomater. 9 (2013) 6630-6640.

[21] E. Polykandriotis, A. Arkudas, R.E. Horch, U. Kneser, G. Mitchell, To matrigel or not to matrigel, Am. J. Pathol. 172 (2008) 1441-1442.

[22] J. Borges, J.F. Mano, Molecular interactions driving the layer-by-layer assembly of multilayers, Chem. Rev. 114 (2014) 8883-8942.

[23] R.R. Costa, J.F. Mano, Polyelectrolyte multilayered assemblies in biomedical technologies, Chem. Soc. Rev. 43 (2014) 3453-3479.

[24] S.M. Oliveira, T.H. Silva, R.L. Reis, J.F. Mano, Nanocoatings containing sulfated polysaccharides prepared by layer-by-layer assembly as models to study cellmaterial interactions, J. Mater. Chem. B 1 (2013) 4406-4418.

[25] K. Gaengel, C. Betsholtz, Endocytosis regulates VEGF signalling during angiogenesis, Nat. Cell Biol. 15 (2013) 233-235.

[26] S.M. Oliveira, V.E. Santo, M.E. Gomes, R.L. Reis, J.F. Mano, Layer-by-layer assembled cell instructive nanocoatings containing platelet lysate, Biomaterials 48 (2015) 56-65.

[27] J. Kreuger, D. Spillmann, J.P. Li, U. Lindahl, Interactions between heparan sulfate and proteins: the concept of specificity, J. Cell Biol. 174 (2006) 323327.

[28] G.S. Schultz, A. Wysocki, Interactions between extracellular matrix and growth factors in wound healing. Wound Repair Regen. 17 (2009) 153-162.

[29] S.K. Nigam, K.T. Bush, Growth factor-heparan sulfate "switches" regulating stages of branching morphogenesis, Pediatr. Nephrol. 29 (2014) 727-735.

[30] T.H. Nguyen, S.H. Kim, C.G. Decker, D.Y. Wong, J.A. Loo, H.D. Maynard, A heparin-mimicking polymer conjugate stabilizes basic fibroblast growth factor, Nat. Chem. 5 (2013) 221-227.

[31] T.N. Vo, F.K. Kasper, A.G. Mikos, Strategies for controlled delivery of growth factors and cells for bone regeneration, Adv. Drug Delivery Rev. 64 (2012) 1292-1309

[32] T.H. Silva, A. Alves, B.M. Ferreira, J.M. Oliveira, L.L. Reys, R.J.F. Ferreira, R.A. Sousa, S.S. Silva, J.F. Mano, R.L. Reis, Materials of marine origin: a review on polymers and ceramics of biomedical interest, Int. Mater. Rev. 57 (2012) 276307.

[33] K. Senni, J. Pereira, F. Gueniche, C. Delbarre-Ladrat, C. Sinquin, J. Ratiskol, G. Godeau, A.M. Fischer, D. Helley, S. Colliec-Jouault, Marine polysaccharides: a source of bioactive molecules for cell therapy and tissue engineering, Mar. Drugs 9 (2011) 1664-1681.

[34] J.F. Mano, G.A. Silva, H.S. Azevedo, P.B. Malafaya, R.A. Sousa, S.S. Silva, L.F. Boesel, J.M. Oliveira, T.C. Santos, A.P. Marques, N.M. Neves, R.L. Reis, Natural origin biodegradable systems in tissue engineering and regenerative medicine: present status and some moving trends, J. R. Soc. Interface 4 (2007) 999-1030.

[35] S.M. Oliveira, R.L. Reis, J.F. Mano, Assembling human platelet lysate into multiscale 3D scaffolds for bone tissue engineering, ACS Biomater. Sci. Eng. 1 (2015) 2-6.

[36] J.F. Mano, Designing biomaterials for tissue engineering based on the deconstruction of the native cellular environment, Mater. Lett. 141 (2015) 198-202.

[37] M.G. Lampugnani, F. Orsenigo, M.C. Gagliani, C. Tacchetti, E. Dejana, Vascular endothelial cadherin controls VEGFR-2 internalization and signaling from intracellular compartments, J. Cell Biol. 174 (2006) 593-604.

[38] P.J. Stahl, T.R. Chan, Y.I. Shen, G. Sun, S. Gerecht, S. Yu, Capillary network-like organization of endothelial cells in PEGDA scaffolds encoded with angiogenic signals via triple helical hybridization, Adv. Funct. Mater. 24 (2014) 32133225.

[39] A. Sahni, C.W. Francis, Stimulation of endothelial cell proliferation by FGF-2 in the presence of fibrinogen requires av332004, Blood 104 (2004) 3635-3641.

[40] J.A. Madri, S.K. Williams, Capillary endothelial cell cultures: phenotypic modulation by matrix components, J. Cell Biol. 97 (1983) 153-165.

[41] G. Ferrari, B.D. Cook, V. Terushkin, G. Pintucci, P. Mignatti, Transforming growth factor-beta 1 (TGF- $\beta 1$ ) induces angiogenesis through vascular endothelial growth factor (VEGF)-mediated apoptosis, J. Cell. Physiol. 219 (2009) 449-458.

[42] R. Mammadov, B. Mammadov, S. Toksoz, B. Aydin, R. Yagci, A.B. Tekinay, M.O. Guler, Heparin mimetic peptide nanofibers promote angiogenesis, Biomacromolecules 12 (2011) 3508-3519.

[43] K.P. Claffey, Molecular profiling of angiogenic markers: a step towards interpretive analysis of a complex biological function, Am. J. Pathol. 161 (2002) 7-11.

[44] A.D. Grove, V.V. Prabhu, B.L. Young, F.C. Lee, V. Kulpa, P.J. Munson, E.C. Kohn, Both protein activation and gene expression are involved in early vascular tube formation in vitro, Clin. Cancer Res. 8 (2002) 3019-3026.

[45] G. Seghezzi, S. Patel, C.J. Ren, A. Gualandris, G. Pintucci, E.S. Robbins, R.L. Shapiro, A.C. Galloway, D.B. Rifkin, P. Mignatti, Fibroblast growth factor-2 (FGF-2) induces vascular endothelial growth factor (VEGF) expression in the endothelial cells of forming capillaries: an autocrine mechanism contributing to angiogenesis, J. Cell Biol. 141 (1998) 1659-1673.

[46] J. Gavard, V. Patel, J.S. Gutkind, Angiopoietin-1 prevents VEGF-induced endothelial permeability by sequestering Src through mDia, Dev. Cell 14 (2008) 25-36.

[47] S.P. Ngok, R. Geyer, M. Liu, A. Kourtidis, S. Agrawal, C. Wu, H.R. Seerapu, L.J. Lewis-Tuffin, K.L. Moodie, D. Huveldt, R. Marx, J.M. Baraban, P. Storz, A. Horowitz, P.Z. Anastasiadis, VEGF and Angiopoietin-1 exert opposing effects on cell junctions by regulating the Rho GEF Syx, J. Cell Biol. 199 (2012) 11031115.

[48] T.I. Koblizek, C. Weiss, G.D. Yancopoulos, U. Deutsch, W. Risau, Angiopoietin-1 induces sprouting angiogenesis in vitro, Curr. Biol. 8 (1998) 529-532.

[49] M. Hangai, T. Murata, N. Miyawaki, C. Spee, J.I. Lim, S. He, D.R. Hinton, S.J. Ryan, Angiopoietin-1 upregulation by vascular endothelial growth factor in human retinal pigment epithelial cells, Invest. Ophthalmol. Vis. Sci. 42 (2001) 16171625.

[50] W.H. Zhu, A. MacIntyre, R.F. Nicosia, Regulation of angiogenesis by vascular endothelial growth factor and angiopoietin-1 in the rat aorta model: distinct temporal patterns of intracellular signaling correlate with induction of angiogenic sprouting, Am. J. Pathol. 161 (2002) 823-830.

[51] S. Kanda, H. Kanetake, Y. Miyata, Role of Src in angiopoietin 1-induced capillary morphogenesis of endothelial cells: Effect of chronic hypoxia on Src inhibition by PP2, Cell. Signal. 19 (2007) 472-480.

[52] N. Eter, M. Spitznas, DMSO mimics inhibitory effect of thalidomide on choriocapillary endothelial cell proliferation in culture, Br. J. Ophthalmol. 86 (2002) 1303-1305.

[53] K. Koizumi, Y. Tsutsumi, Y. Yoshioka, M. Watanabe, T. Okamoto, Y. Mukai, S. Nakagawa, T. Mayumi, Anti-angiogenic effects of dimethyl sulfoxide on endothelial cells, Biol. Pharm. Bull. 26 (2003) 1295-1298. 